\title{
TURISMO E TRANSFORMAÇÕES SOCIOESPACIAIS: uma aproximação teórica e conceitual
}

\section{TOURISM AND SOCIO-SPACIAL TRANSFORMATIONS: a theoretical and conceptual approximation}

\author{
Ana Matilde Vasconcelos do Nascimento (NASCIMENTO, A. M. V. do) \\ Lorena Kallyni Silva Rocha (ROCHA, L. K. S.) ${ }^{* *}$ \\ Francisco Fransualdo de Azevedo (AZEVEDO, F. F. de) \\ Ione Rodrigues Diniz Morais (MORAIS, I. R. D.)
}

\begin{abstract}
RESUMO - O trabalho ora apresentado tem por objetivo discutir os impactos ocasionados pelas transformações socioespaciais decorrentes do turismo. Tais impactos seguem a lógica da globalização dos lugares, que altera as relações de sociabilidade e a própria natureza produzindo-lhes um caráter espetacular e mercantil. Dessa forma, os gestores do turismo acabam se apropriando do tempo livre e das paisagens (naturais e artificiais) para comercializá-los, modificando o significado de uso do território enquanto mercadoria portadora de valor de troca. Este artigo apresenta uma abordagem teórica e conceitual acerca do turismo e das transformações socioespaciais no qual se reflete também sobre a relação entre esta atividade econômica e o desenvolvimento local e o papel que assumem as instâncias de governança de articular, propor e acompanhar o planejamento e a implementação de estratégias que podem conduzir ao turismo sustentável.
\end{abstract}

Palavras-chave: Turismo; Transformações socioespaciais; Desenvolvimento local.

ABSTRACT - The paper presented aims to discuss the impacts caused by socio-spatial transformations resulting from tourism. Such impacts follow the logic of globalization places, which change the relations of sociability and the nature producing a spectacular and mercantile character. Thus, the tourism managers use to appropriate the free time and landscapes (natural and artificial) to market them, changing the meaning of the land

\footnotetext{
* Graduação em Turismo pela Universidade Federal do Rio Grande do Norte (UFRN). Mestranda em Turismo pela UFRN. Endereço para correspondência: Programa de Pós-graduação em Turismo/ PPGTUR. Campus Universitário (UFRN). CEP: 59072-970 - Natal - Rio Grande do Norte (Brasil). Fone/Fax: (0**84) 3215-3617. E-mail: ana.tilde@ hotmail.com.

** Graduação em Turismo pela UFRN. Mestranda em Turismo pela UFRN. Endereço para correspondência: Programa de Pós-graduação em Turismo/ PPGTUR. Campus Universitário - UFRN. CEP: 59072-970 - Natal - Rio Grande do Norte (Brasil). Fone/Fax: (0**84) 3215-3617. E-mail: turismologalore@gmail.com.

*** Doutorado em Geografia pela Universidade Federal de Uberlândia (UFU). Professor Adjunto do Departamento de Geografia da UFRN. Docente dos Programas de Pós-Graduação em Geografia (PPGe) e turismo (PPGTur). Pesquisador do CNPQ. Endereço para correspondência: Universidade Federal do Rio Grande do Norte, Departamento de Geografia. Campus Universitário. CEP: 59072-970 - Natal - Rio Grande do Norte (Brasil). Fone: (0**84) 32153569. E-mail: ffazevedo@gmail.com

****Doutorado em Ciências Sociais pela UFRN. Professora Adjunta do Departamento de Geografia da UFRN. Endereço para correspondência: Universidade Federal do Rio Grande do Norte, Departamento de Geografia. Campus Universitário. CEP: 59078-970 - Natal - Rio Grande do Norte (Brasil). Fone: (0**84) 32153644. E-mail: ionerdm@yahoo.com.br
} 
and using them as commodities and given them some value. This paper presents a theoretical and conceptual approach a tourism and socio-spatial transformations in which is also reflected on the relationship between this economic activity and local development and the role that the governance instances assume in jointing, proposing and overseeing the planning and the implementation of strategies that can lead to sustainable tourism.

Key words: Tourism; Socio-spatial transformations; Local development. 


\section{INTRODUÇÃO}

Para muitos governos o turismo é um poderoso aliado para promover o desenvolvimento regional e local. Segundo Rodrigues (2000) o turismo é a principal atividade econômica do mundo, superando o petróleo em geração de divisas internacionais, passando a ser objeto de desejo de muitas regiões do planeta. Neste sentido, vislumbra-se que o contraponto a esse modelo de turismo que degrada, se institui pela adoção do turismo sustentável, o qual é colocado como uma alternativa ao modelo de desenvolvimento dominante na maioria dos países. A adoção do conceito de desenvolvimento sustentável aplicado ao turismo representa uma estratégia para se equacionar a difícil relação entre o uso turístico do espaço, a preservação do meio ambiente e a melhoria das condições de vida das comunidades locais. Assim, requisitase o apoio do Estado, como sendo a entidade estruturada e legítima da sociedade, que deve definir políticas setoriais que atendam as necessidades do setor turístico. Tal prerrogativa deve ser aliada a uma gestão participativa, democrática, que estimule a discussão e proposição de possibilitar formas concretas de promoção do turismo sustentável, economicamente viável e socialmente justo. A atividade turística é complexa e compreende o consumo, a produção e apropriação do espaço, das paisagens atraentes e exóticas, transformando-as em lugares que são alvo dos turistas e também devem ser valorizados pelos nativos.

Neste processo, coloca-se como um desafio para os atores sociais, renunciar ao turismo de massa, gerador de vultosos rendimentos, e implementar o turismo sustentável como sendo uma alternativa para o desenvolvimento local.

As Instâncias de Governança são fundamentais para que os atores sociais como o poder público e privado, as ONG's e a comunidade em geral possam tomar decisões em conjunto, além de planejar o turismo de maneira articulada.

Todavia, o presente artigo traz discussões sobre a produção do turismo no espaço, desenvolvimento endógeno, desenvolvimento sustentável, a importância do planejamento no turismo, além de apresentar reflexões sobre o papel das instâncias de governança nessa atividade.

Entender o fenômeno turístico é complexo, desse modo, articular o desenvolvimento sustentável para apreender os seus problemas sociais, culturais, 
ecológicos, espaciais e econômicos é um caminho alternativo para se pensar nas possibilidades de minimizar os impactos negativos que a atividade provoca. Além disso, as instâncias de governança por se caracterizar em uma ação coletiva com poder compartilhado, muitas vezes, ajudam a entender esse processo.

\section{TURISMO E ESPAÇO: DA PRODUÇÃO AO CONSUMO}

A sociedade contemporânea enfrenta desafios decorrentes das transformações provocadas pelo processo de globalização que se efetivou no âmbito do sistema capitalista. Nesse processo, o espaço tem papel fundamental na medida em que assume a condição de mercadoria, portanto, possui um valor de troca. Neste contexto, cada vez mais o espaço é produzido por novos atores sociais vinculados a atividades econômicas, por exemplo, o turismo.

A expansão da atividade turística, nos últimos decênios, propiciou a valorização do espaço geográfico tendo em vista a tendência apresentada pelo turista de apreciar as paisagens naturais, exóticas e do meio rural, a partir da idealização de um estilo de vida, que possibilite um contato maior com a natureza. Dessa forma, o aumento do consumo turístico de espaços tornou-se a base fundamental para a realização desta atividade, cujo desenvolvimento segue a lógica do capitalismo, o qual considera que tudo é transformado em mercadoria e possui um custo.

O espaço geográfico é o local onde se realiza e se manifesta a vida social. Com isso, a dinâmica social materializa-se no espaço transmitindo-lhe forma-conteúdo. Neste processo, simultaneamente o espaço se diferencia e se integra, visto que a diferenciação implica em interação. Desta forma, é na diferença que reside o valor do espaço, pois é a partir dos seus atributos específicos que se encontram respostas para a lógica da localização das atividades humanas. Neste cenário se insere a lógica de apropriação do espaço que ocorre a partir da execução de atividades turísticas. Para Fonseca (2005, p. 32), o turismo é uma atividade baseada no consumo do espaço geográfico. Nessa perspectiva, para que uma localidade torne-se objeto de desejo de consumo turístico deve apresentar características que possibilitem a atração de visitantes. A valorização de 
determinadas características do espaço geográfico (naturais ou culturais) varia em função dos gostos e modismo, ao longo do tempo.

O espaço geográfico é marcado pela diversidade dos elementos naturais e culturais que o compõem, gerando paisagens variadas. Para que os recursos naturais possam ser ofertados e consumidos turisticamente é preciso adequá-los para que se tornem um produto turístico. Entretanto, os produtos turísticos elaborados e disponíveis no mercado são bem mais reduzidos. Os atributos essenciais ao espaço podem ser considerados atrativos turísticos pelo modo de pensar e sentir coletivos. Portanto, os gostos e o estilo de vida de uma determinada sociedade definem a demanda social por um dado produto turístico. (FONSECA, 2005).

A imagem de um lugar assume relevância na escolha dos locais que merecem ser visitados, sendo este um aspecto muito explorado pela mídia na comercialização do produto turístico. As características dos locais que contenham função turística são de fundamental importância, mas, podem tornar-se impróprias ao consumo turístico, visto que a natureza geográfica do turismo se reflete na dimensão econômica. Assim, a imagem de uma determinada localidade que enfrenta problemas socioculturais poderá repercutir negativamente e consequentemente afastar turistas.

Para Yázigi (1999, p. 16), a viagem e o turismo são deslocamentos os quais propiciam experiências culturais, por meio da visibilidade, do imaginário e de representações das paisagens. A dimensão visual da paisagem é composta por elementos naturais, artificiais e constitui o principal apelo de atratividade do lugar. (YÁZIGI, 1999).

Nesse sentido, a função dos responsáveis pelo turismo é criar e recriar espaços diversificados, por meio de uma dinâmica em que os espaços produzidos caracterizamse como homogêneos e excludentes. Mundialmente, assume-se como referência do modelo de produção de espaços turísticos a Disney, Las Vegas, dentre outros. São espaços produzidos artificialmente pelo e para o turismo. Portanto, a paisagem artificial do turismo, resulta da captação do imaginário coletivo, sendo reforçado pela mídia a qual mantém o processo cada vez mais fantasioso.

Nessa perspectiva, oportuno questionar como será a paisagem do futuro. $\mathrm{Na}$ sociedade em que a celeridade e a instantaneidade são marcas, alguns espaços produzidos para o turismo perdem sentido, tornam-se sem identidade, ou seja, são 
espaços que se transformam em cenário para o espetáculo, sendo denominados como, Não-lugares. (RODRIGUES, 2000). Nestes, são produzidos simulacros de lugares que determinam comportamentos e atitudes de apropriação desses lugares, os quais podem ser vistos, fotografados e depois esquecidos.

Essa é uma lógica que contraria a definição de lugar, que é em sua essência produção humana, visto que se reproduz na relação entre espaço e sociedade, o que significa criar e estabelecer uma identidade entre a comunidade e um lugar, o homem se reconhece porque vive nele (YÁZIGI, 1999, p. 29).

Considerando a dinâmica do turismo, tem-se que, em algumas situações alguns pacotes turísticos ao controlar, delimitar hora, lugar, tempo destinado a cada atração, além do que deve ser visto ou não pelo turista, acabam por ignorar a identidade, o modo de vida e a cultura de um lugar, banalizando-o.

Com isso, alguns turistas acabam por assumir uma postura passiva e de sujeição, na qual se deixa levar por um programa do guia e pelas orientações da agência de viagens e da operadora de turismo.

Na relação entre turismo e espaço, em última análise, é importante ressaltar que o poder público assume importância, no que diz respeito, a gestão do uso do espaço, assumindo maior responsabilidade de solucionar os conflitos e definir políticas setoriais relativas à sua apropriação e uso. Tal postura deve estar baseada em iniciativas que privilegiem o debate entre os agentes sociais envolvidos, incluindo a comunidade. Esta estratégia se constitui fundamental para que o desenvolvimento da atividade turística de um local ocorra, de maneira sustentável, conservando os elementos naturais e socioculturais, contidos no espaço geográfico que constituem-se de atrativos.

\section{DESENVOLVIMENTO ENDÓGENO COMO DESAFIO PARA O TURISMO}

O desenvolvimento endógeno é uma interpretação que explica os processos de acumulação de capital, bem como identifica mecanismos que contribuem para o aumento da produtividade e da competitividade de cidades (BENI, 2006, p. 35). Tratase de uma interpretação voltada para a ação, em que a sociedade civil se mostra capaz de oferecer uma resposta aos desafios produzidos pelo aumento da concorrência nos 
mercados por meio, da atuação de políticas públicas setoriais, da gestão do desenvolvimento social, participativo. Fazem parte do desenvolvimento local, o gerenciamento econômico, os orçamentos, as associações, os planejadores, a sociedade civil, as Organizações Não Governamentais - ONG's, as instituições públicas e privadas (responsabilidade social corporativa), os meios tecnológicos e informacionais, a inovação e as instâncias de governança. (SACHS, 1993). A atuação desses atores sociais e a disposição desses instrumentais possibilitam o desenvolvimento econômico, social e cultural da população de um local, que possui condições para se organizar e evitar que agentes externos limitem suas potencialidades.

Com base nesta concepção de desenvolvimento endógeno, infere-se que a ação governamental por meio de políticas públicas torna-se importante para a sua implementação. Segundo Hall (2004, p. 26), as políticas públicas são atos que o governo decide ou não, realizar. Assim, considerando-se que a atividade turística tem no Estado um dos seus agentes de desenvolvimento, a definição de políticas públicas para o setor se apresenta como requisito que não deve ser negligenciado.

De acordo com Rodrigues (2000, p. 19), os elementos metodológicos relevantes para a reflexão sobre o significado do turismo para o desenvolvimento é saber quem ganha ou tende a ganhar e quem perde (ou pode perder) com essa atividade. Assim, a autora propõe três grupos principais de indivíduos: a população da área de origem dos turistas, os turistas e a população da área de destino dos turistas. A análise sobre quem perde ou ganha com o turismo deve considerar a autonomia da população de um local para que esta atinja um desenvolvimento socioespacial. Essa perspectiva de desenvolvimento pressupõe que a coletividade tenha autonomia para gerir os seus destinos e eleger conscientemente suas prioridades e os meios para concretizá-las.

Cabe frisar que, há graus de complexidade diferentes, em função do menor ou maior contraste produzido pelo contato regular entre grupos socioeconômicos e culturalmente distintos. Pode se considerar como exemplo, um grupo que busca lazer, que possui maior poder de compra podendo induzir alguns indivíduos da população mais pobre, à prostituição - adulta e infantil, ao consumo de drogas, ao crime, ao crescimento urbano descontrolado, entre outros. (RODRIGUES, 2000).

Assim, o turismo é sócio-espacialmente impactante devido aos fluxos de pessoas que movimentam recursos financeiros. Isso pode ser considerado bom ou ruim, do 
ponto de vista do desenvolvimento, dependendo: do que se entende por desenvolvimento; da natureza do turismo (caráter predatório ou não e grau de contraste sociocultural, socioeconômico e cultural entre os grupos humanos envolvidos); e de quais grupos ou segmentos sociais, específicos referentes à área de destino turístico se esteja tratando.

Portanto, ao se refletir sobre desenvolvimento endógeno deve-se ter em mente a dimensão socioespacial, pressupondo que uma comunidade precisa ter autonomia para gerir os seus destinos. É indiscutível que, o turismo deve contribuir para um desenvolvimento de base local, contemplando as potencialidades do lugar valorizando as manifestações culturais e a construção de identidades. Para isso, faz-se necessária à implementação de políticas públicas setoriais, que solucionem ou mitiguem problemas básicos relacionados à infraestrutura, meio ambiente, educação, saúde, segurança e desigualdades sociais. Requisita-se uma gestão territorial que assuma o desafio de aliar prática e teoria e que leve em conta o sucesso e o fracasso das experiências vivenciadas na comunidade.

Nessa perspectiva é possível pensar o turismo como atividade econômica propulsora do desenvolvimento local.

\section{DESENVOLVIMENTO SUSTENTÁVEL E ATIVIDADE TURÍSTICA}

No ano de 1972 realizou-se em Estocolmo a Conferência das Nações Unidas (ONU) sobre o Meio Ambiente e Desenvolvimento, na qual foi recomendada a criação do Programa das Nações Unidas para o Meio Ambiente (PNUMA) (BARBIERI, SILVA, 2011). No âmbito das discussões sobre os efeitos e as causas dos problemas ambientais que passaram a ser denunciados, surgiram as primeiras referências sobre a noção de sustentabilidade. Por meio do Relatório Brundtland ${ }^{1}$ foi consolidado o conceito de desenvolvimento sustentável, definido como aquele que atende as necessidades do presente sem comprometer a possibilidade das gerações futuras de atenderem as suas próprias necessidades (RODRIGUES, 2000). Enquanto conceito, o

Consultar versão original do Relatório Brundtland, 1987. Disponível em: <http://ambiente.files.wordpress.com/2011/03/brundtland-report-our-common-future.pdf>. Acesso em: 12/07/2012. 
desenvolvimento sustentável foi consagrado na ECO92, realizada no Rio de Janeiro, apesar da distância ainda existente entre realidade e abordagem conceitual. (RODRIGUES, 2000) O decurso do tempo revela que os problemas ambientais e sociais ainda continuam sendo frequentemente negligenciados pelas políticas setoriais, no âmbito nacional e regional.

Nesse sentido, na tentativa de superar o modelo de desenvolvimento turístico até então adotado, que se mostrou predatório, surgiu à proposta do turismo sustentável (durável). Aplicado ao turismo, o princípio da sustentabilidade é definido como algo que vai além da dimensão ecológica, pois compreende a melhoria das condições econômicas e sociais das populações locais e a satisfação dos turistas. Swarbrooke (2000, p. 19) indica que os tipos de turismo que são altamente compatíveis com o conceito de turismo sustentável são o ecoturismo, o turismo cultural, o agroturismo (turismo rural em pequena escala) que representa fonte de renda para os trabalhadores do campo, as férias de conservação (onde turistas fazem ações conservacionistas) e as atrações urbanas em localidades turísticas abandonadas (alvo de revitalização).

Em síntese, o turismo sustentável está fundamentado, segundo Sachs (1993, p. 37), na Sustentabilidade Ecológica, entendida como a proteção da natureza e da diversidade biológica (o desenvolvimento turístico deve respeitar a capacidade de suporte); Sustentabilidade Social, que deve conduzir a redução das atuais diferenças sociais e a garantia dos direitos de cidadania; Sustentabilidade Cultural que busca soluções no âmbito local, utilizando-se das potencialidades das culturas específicas, considerando a matriz cultural e o modo de vida de um local, de forma que, a comunidade faça parte dos processos decisórios e na formulação e gestão de programas e planos de desenvolvimento turístico; a Sustentabilidade Econômica que assegura o desenvolvimento econômico para as gerações atuais e o manejo dos recursos naturais; a Sustentabilidade Espacial que se baseia na distribuição geográfica mais equilibrada para evitar alta concentração de pessoas, equipamentos e de infraestrutura, diminuindo a destruição de ecossistemas frágeis e degradação da qualidade da experiência do turista.

$\mathrm{Na}$ atividade turística a motivação dos consumidores significa a constante procura por novidades, decorrentes da saturação dos roteiros globais do turismo tradicional e de massa. (YÁZIGI, 1999). Os princípios balizadores do turismo sustentável não são incorporados assim como a prática do planejamento territorial e as 
políticas de turismo (RODRIGUES, 2000). O planejamento é praticado dentro de uma visão centralizadora, burocrática, setorizado, e como algo a ser imposto de cima para baixo, postura herdada da racionalidade dominante dos anos 70. (BENI, 2006). Percebese que, nesse período, as políticas territoriais voltadas para o desenvolvimento econômico e social atendiam interesses dos poderes político e institucional, representados pelos governos centrais.

Em suma, o turismo tendo sido estudado sob variadas formas, com ênfase na sua dimensão econômica. Logo, o grande desafio para os agentes do turismo é implementar estratégias e ações (planos, projetos, programas) referendados por práticas sustentáveis para que sejam obtidas vantagens competitivas duradouras e contribuições que se traduzam em impactos socioeconômicos, ambientais e culturais positivos.

\section{A IMPORTÂNCIA DO PLANEJAMENTO NO TURISMO}

O planejamento e o processo de gestão do Turismo são dois fatores importantes para a prática sustentável da atividade, pois contribuem para o aumento dos benefícios sociais, culturais e econômicos. Outrossim, ajudam a diminuir os impactos negativos nas regiões que buscam o desenvolvimento dessa atividade, facilitando à comunidade, à iniciativa privada e à iniciativa pública a participação no processo de tomada de decisão dos municípios, ou seja, contribuem para o desenvolvimento do turismo minimizando os impactos ambientais.

Para Hall (2004, p. 24):

\footnotetext{
Planejar é o processo de preparar um conjunto de decisões a serem colocadas em prática no futuro, direcionadas para o cumprimento de metas pelos meios preferidos. Todavia, o processo de planejamento turístico não trata apenas de decidir o que deve ser oferecido no futuro para uma determinada área de terra ou comunidade. $\mathrm{O}$ assunto é muito mais complexo. O planejamento é um tipo de tomada de decisões e elaboração de políticas, ele lida, entretanto, com um conjunto de decisões interdependentes ou sistematicamente relacionadas e não com decisões 'individuais. Planejar é, portanto, apenas uma parte de um processo global de "planejamento-decisão-ação". Além disso, pode ser difícil isolar muitas atividades desse processo, haja vista que o planejamento e outras atividades envolvem aspectos como barganhas e negociação, compromisso, coerção, valores, escolha e política.
} 
O planejamento do turismo é fundamental para colocar em prática ações relevantes para o desenvolvimento de tal atividade. Dessa maneira, podem-se estabelecer os objetivos e as metas que se pretende alcançar, e, sobretudo, o percurso que poderá ser realizado para atingir os resultados que se almeja. Desta forma, "o planejamento turístico não se trata apenas de decidir o que deve ser oferecido no futuro para determinada área ou comunidade." (HALL, 2004, p. 24).

A atividade turística necessita de um bom planejamento e de uma gestão eficiente para que seja trabalhada de forma adequada. Para isso é preciso que o poder público, a iniciativa privada, as ONG's, juntamente com a comunidade, façam parte da tomada de decisões que envolve o seu desenvolvimento.

Conforme Petrocchi (1998, p. 20):

O planejamento - a visão do futuro próximo ou distante - contribui para que tarefas sejam melhor realizadas e objetivos sejam mais facilmente atingidos, por pessoas ou organizações. Ordena as ações e dá prioridade a elas. Permite mapear dificuldades ou obstáculos e, assim, escolher previamente caminhos alternativos.

O desenvolvimento do turismo exige um processo de gestão abrangente e visão de longo prazo. Isto é, requer capacidade administrativa e ações coordenadas e convergentes. Muitas cidades estão destruindo seu potencial turístico por meio de fatores como a saturação, a desordem urbana e a degradação dos meios urbano e natural. (PETROCCHI, 1998).

Vale salientar, que a atividade turística é ainda afligida pela descontinuidade das políticas públicas. É afetada também pela alternância do poder entre grupos políticos rivais, que tendem a deixar de lado as providências em andamento do grupo que foi substituído. Para que o turismo seja bem planejado é necessário se trabalhar com uma abordagem sistematizada e com visão de longo prazo.

Com base em Dias (2008), pode-se definir política pública como o conjunto de ações executadas pelo Estado, enquanto sujeito, direcionadas a atender às necessidades de toda a sociedade. A política pública pode ser entendida como um conjunto de regras e ações que são organizadas e colocadas em prática pelo Governo, imbuída de uma ideologia para o benefício da população.

Conforme Azevedo (2003) as políticas públicas têm duas características gerais. Primeiro, a procura do senso comum em torno do que se pretende fazer e deixar de 
fazer. Assim, quanto maior for o consenso, melhores as condições de aprovação e implementação das políticas propostas. Segundo, a acepção de normas e o processamento de conflitos. Segundo o mesmo autor, as políticas públicas podem definir normas tanto para a ação como para a resolução dos eventuais conflitos entre os diversos indivíduos e agentes sociais.

As políticas públicas podem acontecer de maneira harmônica, umas conexas às outras. Isto é o exercício da intersetorialidade da administração pública a fim de se desenvolver em conjunto com as diversas secretarias do governo, visando o bem social de modo associado.

É importante que os atores envolvidos no planejamento, participem da gestão do município, de forma igualitária, para que não haja exclusão de nenhuma parte, principalmente da comunidade, já que todos são indispensáveis para o desenvolvimento local.

O planejamento é fundamental para auxiliar a determinar quem perde ou ganha no processo de desenvolvimento turístico, além de ajudar a contribuir para formas sustentáveis de turismo nas quais se vê equilíbrio das metas econômicas, ambientais e sociais e que geram resultados mais justos às partes interessadas, ou seja, não apenas os incorporadores, o setor turístico e o turista, mas também a comunidade cujo destino está sendo consumido. (HALL, 2004).

Segundo Petrocchi (1998) a atividade turística passa pela conscientização da população acerca de sua importância, sendo este um fator determinante na definição de sua gestão. Para o autor, se é necessária a participação da comunidade, que ela seja ampla e integral, principalmente por parte dos empresários e pequenos investidores do turismo. Essa participação deve, por conseguinte, acontecer também no estabelecimento das normas e regulamentos do turismo. $\mathrm{O}$ autor ainda argumenta que, o programa de normalização deve ser estabelecido, monitorado e atualizado de forma compartilhada entre o Poder Público e a comunidade.

Para Dias (2008) levando em conta o uso do espaço, o planejamento se constitui numa técnica indispensável às administrações públicas municipais que acreditam no desenvolvimento do turismo. Assim, o planejamento é imprescindível porque um território é um componente básico do desenvolvimento turístico, visto que abriga os recursos ambientais e culturais dos destinos turísticos, além de ser o espaço físico 
destinado à instalação da infraestrutura e dos equipamentos que irão receber o fluxo de visitantes.

Para Tyler; Guerrier e Robertson (2001), grande parte das decisões importantes que moldam a natureza do desenvolvimento turístico de determinada localidade não é tomada apenas por planejadores, mas também por políticos e outras partes interessadas no assunto. Políticos e demais influenciadores são os responsáveis pela formatação dos objetivos que orientam os planos - em muitos casos, são eles que delineiam a natureza da participação pública e fornecem os valores políticos e sociais de uma sociedade, valores capazes de levar à aceitação ou não do processo e dos produtos finais de um planejamento turístico.

"O planejamento pode ser visto como um processo decisório". Entretanto o processo de planejamento turístico não diz respeito apenas a decidir o que deve ser feito no futuro. Trata-se de algo bem mais complexo do que isso." (TYLER ; GUERRIER; ROBERTSON, 2001, p. 24).

O planejamento e gestão do turismo são fundamentais para garantir a sustentabilidade, não apenas da atividade turística, mas também da parte socioambiental em que a mesma se desenvolve. Essas ferramentas colaboram para que a atividade turística se desenvolva sem provocar malefícios a suas próprias fontes de existência.

Com isso, a organização de qualquer instância de agentes sociais, seja a das redes de conselhos, consórcios, ou outros, pode proporcionar o desenvolvimento de políticas públicas mais específicas e mais diretamente articuladas de acordo com as necessidades e características do setor turístico regional.

Nesse contexto, percebe-se o quanto o planejamento é indispensável em várias esferas, principalmente, no que diz respeito ao desenvolvimento local, a fim de maximizar a participação da população no processo de decisão e participação das políticas.

Conforme Rodrigues (2000), o desenvolvimento local aparece como uma alternativa pensada a respeito da sustentabilidade e, sobretudo, refletida na escala do desenvolvimento humano, fomentado a partir de iniciativas das comunidades locais. As estratégias de desenvolvimento local são a saída para as pequenas localidades enfrentarem o processo incessante da globalização que vem provocando uma reestruturação da economia mundial. 
O fenômeno da globalização chegou a patamares indiscutíveis em diversos setores, como o setor econômico. Esse processo gerou o aumento da concorrência e, em decorrência disso, houve um crescimento no número de desempregados devido à inserção das tecnologias de produção no mercado. A globalização acarretou fatores, que dependendo da maneira que se interprete, pode ser considerado como impactos positivos ou negativos. Conforme Rodrigues (2000), na contracorrente da globalização, seja ela perversa ou não, o lugar surge com toda a força, pois é nos fragmentos que se verifica o global. O global não significa homogêneo, nem uniforme; pelo contrário, o global se alimenta das diferenças. Esse é um ponto de reflexão importante para os estudiosos do turismo, uma vez que a atividade vive das especificidades dos lugares. Quase todos partem em busca do novo, do diferente, do exótico. Há que reforçar o lugar na sua expressão identidária, sem que isso signifique isolamento. São poucas as áreas do planeta que estão fora da globalização. (RODRIGUES, 2000).

Para Cruz (2007), a maneira como uma pequena indústria, voltada para um mercado consumidor regional, participa da produção do espaço é diferente, por exemplo, daquela de indústrias multinacionais, muito mais exigentes no que diz respeito à disponibilidade de infraestrutura e à eficiência e rapidez dos fluxos. Por outro lado, a hegemonia de um e de outro não invalida as possibilidades de contramovimentos. A sociedade civil está organizada, seja nas formas de associações, de Organizações Nãogovernamentais, ou outras, pode "tomar para si as rédeas do processo", como explicam experiências nas escalas local e regional. A ausência ou ineficiência do Estado e a voracidade conquistadora de agentes de mercado obrigam sociedades a reagirem na luta diária pela sobrevivência.

Nesse contexto, delineia-se a realidade que o turismo enfrenta, ou seja, não passa de uma pequena parcela do grande jogo de relações econômicas, sociais, espaciais.

"Se a produção do espaço é um processo complexo e conflituoso, entender a participação do turismo nele requer o desvendamento de sua natureza, de sua complexidade e de seus conflitos.” (CRUZ, 2007, p. 11).

Para a autora, o uso do espaço pela atividade turística forma o que se conhece como "território turístico", isto é, pequenas partes do espaço geográfico em que a produção do turismo foi e ainda é decisiva. Com isso, o que se observa é que o turismo nasce como um dos vieses para a procura de crescimento local sem necessitar que neste 
se efetive o padrão de desenvolvimento que a globalização impõe, havendo, desigualdade entre os meios, visto que, uma localidade em todos os casos é afetada com a deteriorização de suas riquezas naturais e culturais.

Dessa maneira, compreende-se o quanto o planejamento no turismo é importante para o desenvolvimento de um local, levando em consideração o fato de ser um processo contínuo, que necessita estar constantemente em avaliação e, à medida que for necessário, ser submetido a alterações e mudanças para responder as novas exigências da globalização, sem comprometer o uso do espaço e os princípios da sustentabilidade.

\title{
6 DISCUTINDO O PAPEL DAS INSTÂNCIAS DE GOVERNANÇA
}

O termo "governança" foi definido pelo Programa de Desenvolvimento das Nações Unidas (PNUD apud REIS, 2011, p. 2)² como:

\begin{abstract}
O exercício do poder econômico, político e administrativo para a gestão dos assuntos do país, em todos os níveis. É composto pelos mecanismos, processos e instituições através dos quais os cidadãos e grupos articulam os seus interesses, exercitam seus direitos legais, cumprem com as suas obrigações e mediam as suas diferenças.
\end{abstract}

Dois aspectos desta definição merecem atenção especial. Primeiro, não obstante o governo ser uma peça fundamental no planejamento e gestão do turismo, o conceito de governança é mais vasto do que o de governo. Governança é normalmente descrito como envolvendo o governo, a sociedade civil e o setor privado. O Good Governance Advisory Group (2004, p. 3) afirma que "boa governança na parte do setor público faz uma contribuição significante na melhoria de vida das populações".

Levando-se em consideração os preceitos da participação, sustentabilidade, integração e descentralização no desenvolvimento local é relevante contar com o engajamento do poder público, dos empresários, da sociedade e das instituições de ensino dos municípios que compõem uma região turística, a fim de fortalecer o desenvolvimento do turismo através da institucionalização de Instâncias de Governança. (BRASIL, 2007, p. 14).

\footnotetext{
${ }^{2}$ PNUD - Programa de las Naciones Unidas para el Desarrollo. Informe la democracia en América Latina: hacia una democracia de ciudadanas e ciudadanos. Buenos Aires: PNUD, 2004.
} 
Segundo Diniz (1995) o termo governança surgiu a partir de reflexões do Banco Mundial, com a finalidade de abranger o conhecimento acerca do processo de gestão do Estado. Tendo em vista aprofundar o conhecimento das condições que garantem um Estado eficiente, tal preocupação deslocou o foco da atenção das implicações estritamente econômicas da ação estatal para uma visão mais abrangente, envolvendo as dimensões sociais e políticas da gestão pública.

A governança requer articulação e transparência no planejamento das políticas públicas do Estado. Com isso, é de suma importância que o Estado e a sociedade civil se articulem para tomar as decisões que repercutem no local.

Putnam (2006), por sua vez, afirma que os sistemas de participação cívica são uma forma fundamental de capital social. Isso quer dizer que quanto mais desenvolvidos forem esses sistemas numa comunidade, maior será a possibilidade de que seus cidadãos sejam capazes de colaborar em prol da coletividade.

No que diz respeito às transformações socioespaciais, a governança tem um papel relevante como mediadora do processo institucional organizacional de construção de uma estratégia para compatibilizar os diferentes modos de coordenação entre atores geograficamente próximos em caráter parcial e provisório, atendendo a premissa de resolução de problemas incomuns.

Para Fuini (2011), concebendo também as estruturas de governança como alavancas da competitividade e do desenvolvimento territorial das regiões e aglomerados produtivos através de seus recursos e ativos territorializados, pode-se considerar que as mesmas englobam as ferramentas sociais e políticas que promovem as metas de obter o máximo de externalidades regionais através da promoção das vantagens competitivas e que, ao mesmo tempo, asseguram que os padrões sociais de coordenação do bem-estar da comunidade sejam preservados.

Conforme Dallabrida (2007), o termo governança territorial se refere às iniciativas ou ações que expressam a capacidade de uma sociedade organizada territorialmente para gerir os assuntos públicos a partir do envolvimento conjunto e cooperativo dos atores sociais, econômicos e institucionais.

Esta estratégia vem ao encontro com o próprio processo de amadurecimento das relações entre os membros engajados nas Instâncias de Governança, isto é, o fato de ocorrer a formalização de um grupo de empresários no âmbito da atividade turística, 
vem a ser consequência de um processo de solidificação de discussões e debates de um grupo que almeja objetivos comuns e que vê na participação coletiva uma forma de obter melhores resultados sociais, sustentáveis, culturais e econômicos para o desenvolvimento local, através de um modelo sólido de Governança (MIELKE; PEREIRA, 2006).

Para que as instâncias de governança cresçam em determinada localidade é fundamental levar a cabo um processo de desenvolvimento, e gestão através de uma governança proativa e presente. Isto envolve o processo como um todo, desde o envolvimento e sensibilização inicial das comunidades locais com os empresários quanto à importância dos projetos e do turismo para a região, até os trabalhos de capacitação no que se refere à própria atividade turística, sobretudo, da gestão e governança corporativa. Porém, para que esse processo ocorra sem degradar os recursos naturais e culturais, é fundamental que se realize um eficiente planejamento das ações e atividades para não inviabilizar o desenvolvimento local sustentável.

Para Mielke e Pereira (2006, p. 44):

\begin{abstract}
A governança não necessariamente deve ser representada por uma instituição, mas fundamentalmente deve existir fazendo parte de uma. [...] joga um papel fundamental na manutenção do vínculo dos atores sociais a uma instituição, pois deve atuar como uma ouvidoria interna do aglomerado tendo alcance entre os diversos setores econômicos envolvidos. O foco da governança é a gestão como um todo e não somente questões relativas a treinamentos e capacitações, e deve representar de fato ao grupo da qual lidera, sendo transparente, democrática e participativa.
\end{abstract}

As instâncias de governança são compostas por indivíduos, grupos ou organizações cuja dinâmica tem como objetivo a perpetuação, a consolidação e o desenvolvimento das atividades dos seus membros, além do processo de tomada de decisões.

Para Amaral (2004), as instâncias de governança possuem as seguintes características: objetivos compartilhados, construídos coletivamente; múltiplos níveis de organização e ação; dinamismo e intencionalidade dos envolvidos; coexistência de diferentes; empoderamento dos participantes; desconcentração do poder; multiiniciativas; ambiente fértil para parcerias, oportunidades para relações multilaterais.

Nesse contexto, as instâncias de governança assumem um papel fundamental na instituição do processo de planejamento das localidades e de implementação de 
programas para fomentar o turismo. Para isso, precisa contar com pessoas especializadas, com competência para promover a negociação e articulação entre os diversos atores envolvidos no planejamento e, depois, na implementação das atividades.

\section{CONSIDERAÇÕES FINAIS}

O turismo apresenta-se como uma forma específica, de produção, consumo, criação e recriação do espaço social, que envolve a lógica capitalista, semelhante às demais atividades econômicas que, produzem mercadorias.

Dessa forma, a lógica do desenvolvimento da atividade turística justifica-se pela diferenciação do espaço (representado pelo produto turístico), que se acentua através do aumento da competitividade existente entre os destinos turísticos. Assim, é preciso entender o fenômeno turístico em sua complexidade. Uma possibilidade é articular à atividade a noção de desenvolvimento sustentável para compreender os problemas sociais, culturais, ecológicos, espaciais e econômicos da comunidade. Em linhas gerais, as instâncias de governança podem contribuir positivamente para tal compreensão, tendo em vista que se fundamentam em uma ação coletiva na qual o poder é compartilhado.

Por fim, a perspectiva de se pensar o desenvolvimento local através do turismo sustentável, requisita renunciar ao turismo massificado, que é grande gerador de recursos financeiros e predatório para diminuir a apreensão social, ou seja, a preocupação com os impactos negativos derivados desta modalidade e, com isso, identificar as organizações que assumem o comprometimento social de agir com ética e contribuir para a melhoria da qualidade de vida da sociedade como um todo.

\section{REFERÊNCIAS}

AMARAL, V. Redes sociais e redes naturais: a dinâmica da vida. Rede de Informações para o Terceiro Setor - Rits. Rio de Janeiro, 2004. Disponível em: <http://www.rits.org.br/redes_teste/rd_tmes_fev2004.cfm>. Acesso em: 10/06/2012. 
AZEVEDO, S. de. Políticas públicas: discutindo modelos e alguns problemas de implementação. In: Santos Júnior, Orlando A. Políticas públicas e gestão local: programa interdisciplinar de capacitação de conselheiros municipais. Rio de Janeiro: FASE, 2003. Disponível em:

<www.fase.org.br/v2/admin/anexos/.../10_Sergio\%20Azevedo_06.doc>. Acesso em: $05 / 05 / 2012$.

BARBIERI, J. C; SILVA, D. da. Desenvolvimento sustentável e educação ambiental: uma trajetória comum com muitos desafios. RAM, VER. ADM. MACKENZIE, v. 12, n. 3, Edição Especial. São Paulo, 2011.

BRASIL, Ministério do Turismo. Institucionalização da instância de governança Regional. Módulo operacional 3. Secretaria Nacional de Políticas de Turismo. Brasília, 2007.

BENI, M. C. Política e planejamento de turismo no Brasil. São Paulo: Aleph, 2006.

CRUZ, R. de C. A. da. Geografias do turismo: de lugares a pseudo-lugares. São Paulo: Roca, 2007.

DALLABRIDA, V. R. Governança territorial: a densidade institucional e o capital social no processo de gestão do desenvolvimento territorial. In: SEMINÁRIO INTERNACIONAL SOBRE DESENVOLVIMENTO, 3., 2007, Santa Cruz do Sul. Anais. Disponível em: <http://www.capitalsocialsul.com.br>. Acesso em: 03/06/2012.

DIAS, R. Planejamento do turismo: política e desenvolvimento do turismo no Brasil. São Paulo: Atlas, 2008.

DINIZ, E. Governabilidade, Democracia e Reforma do Estado: Os Desafios da Construção de uma Nova Ordem no Brasil dos Anos 90. In: DADOS - Revista de ciências sociais. Rio de Janeiro, v. 38, n. 3, 1995. p. 385-415.

FONSECA, M. A. P. Espaço, políticas de turismo e competitividade. Natal: EduFRN, 2005.

FUINI, L. L. A governança territorial e suas manifestações: arranjos produtivos locais (APLS) e circuitos turísticos. Revista da Casa da Geografia de Sobral, Sobral-CE, v. 13, n.1, p. 9-22, 2011. Disponível em:

<http://www.uvanet.br/rcg/vol_13/governaca.pdf>. Acesso em: 20/05/2012.

GOOD GOVERNANCE ADVISORY GROUP. Good Governance Guide: the principals of Good Governance within Local Governments. Good governance advisory group. Melbourne, Australia, 2004.

HALL, M. Planejamento turístico: políticas, processos e relacionamentos. 2. ed. São Paulo: Contexto, 2004. 
MIELKE, E.; PEREIRA, A. Desenvolvimento econômico e social através do turismo: interações entre atores locais. IV SEMINÁRIO DE PESQUISA EM TURISMO DO MERCOSUL / III SEMINÁRIO DA ANPTUR - ASSOCIAÇÃO NACIONAL DE PESQUISA E PÓS-GRADUAÇÃO EM TURISMO. Anais... Caxias do Sul: Brasil, 2006.

PETROCCHI, M. Turismo: planejamento e gestão. São Paulo: Futura, 1998.

PUTNAM, R. D. Comunidade e democracia: a experiência da Itália moderna. 5. ed. Rio de Janeiro: Editora FGV, 2006.

REIS, A. P. A burocracia virtual como ferramenta na elaboração de indicadores da governança: estudo de caso. Niterói, II JORNADA CIENTÍFICA DE ADMINISTRAÇÃO PÚBLICA, Faculdade de Ciências e Letras (Fcl) - UNESP, Rio de Janeiro, 2011. Disponível em:

<http://WWW.jornap.com/IIIJornap/anais/Anais\%20II/Artigos/39>. pdf. Acesso em: 09/05/2012.

RODRIGUES, A. B. Turismo e desenvolvimento local. 2 ed. São Paulo: Hucitec, 2000.

SACHS, I. Estratégias de transições para o século XXI. São Paulo: Brasiliense, 1993.

SWARBROOKE, J. Turismo sustentável: conceitos e impacto ambiental. São Paulo: Aleph, 2000.

TYLER, D.; GUERRIER, Y.; ROBERTSON, M. Gestão de turismo municipal. São Paulo: Futura, 2001.

YÁZIGI, E. Turismo: espaço, paisagem e cultura. 2. ed. São Paulo: Hucitec, 1999.

Recebido em: 18-11-2012

Aprovado em: 18-12-2012 